\title{
Liver receptor homologue 1, a novel prognostic marker in colon cancer patients
}

\author{
CONG WU* , JIN FENG* ${ }^{*}$ LING LI, YUGANG WU, HAIBIN XIE, YONG YIN, JING YE and ZHONG LI \\ Department of General Surgery, The First People's Hospital of Changzhou, \\ The Third Affiliated Hospital of Soochow University, Changzhou, Jiangsu 213000, P.R. China
}

Received November 9, 2017; Accepted April 13, 2018

DOI: $10.3892 / \mathrm{ol} .2018 .8988$

\begin{abstract}
Liver receptor homologue 1 (LRH-1) is an orphan nuclear receptor that is highly expressed in a variety of cancer tissues, promotes tumor cell proliferation and metastasis, and is involved in the tumor cell cycle and apoptosis. The aim of the present study was to assess the association between the expression of LRH-1 and the prognosis of patients with colon cancer. Immunohistochemistry was used to detect the expression of LRH1 in 128 cases of colon cancer and adjacent tissues. The 5-year survival rate was obtained from telephone follow-up data, outpatient review and through access to medical records. Positive expression of LRH-1 was found in 108/128 colon cancer samples, compared with 17/128 normal tissues. Statistical analysis showed that positive LRH-1 expression was significantly associated with clinical pathological stage, depth of invasion and lymph node metastasis. The overall survival (OS) rate of patients with positive LRH-1 expression was significantly lower than that of patients with low expression. Multivariate analysis showed that LRH-1 expression could be used as an independent predictor of OS. In conclusion, the present findings suggest that LRH-1 may serve an important role in the development and progression of colon cancer, with potential value as a prognostic molecular marker that could be used to assist in the diagnosis and evaluation of colon cancer. LRH-1 may become a target for novel therapies for patients with colon cancer.
\end{abstract}

\section{Introduction}

Liver receptor homologue 1 (LRH-1), also known as nuclear receptor subfamily 5 group A member 2 (NR5A2), is a

Correspondence to: Dr Zhong Li, Department of General Surgery, The First People's Hospital of Changzhou, The Third Affiliated Hospital of Soochow University, 185 Juqian Street, Changzhou, Jiangsu 213000, P.R. China

E-mail: lizhong9138@163.com

*Contributed equally

Key words: liver receptor homologue 1, colon cancer, immunohistochemistry, prognosis member of the NR5A subfamily of NRs that was originally found in the liver of mice, and then later in rats, chickens, horses, zebrafish, frogs and the human body (1). Since then, it has been shown to be involved in the development of a variety of malignant tumors, including breast, liver, gastric, colon and pancreatic cancer (2-4). LRH-1 is involved in regulating numerous functions, with studies showing that it participates in the metabolism, differentiation and development of organisms (4-6). LRH-1 also regulates a variety of biological processes, including bile acid metabolism (7), reverse cholesterol transport (8) and glucose balance in the human body (9). Recently, LRH-1 was found to serve a decisive role in controlling the development of neural stem cells (10). Therefore, LRH-1 has been identified as a specific tumor marker for the evaluation of disease in patients with cancer.

The association between the expression and prognosis of LRH-1 in malignant tumors has been investigated by certain studies. Although, it has been shown that LRH-1 is highly expressed in colon cancer (11), there is no research showing the association between its positive expression and prognosis. The following study was undertaken in order to investigate the expression of LRH-1 in colon cancer and its association with the prognosis of affected patients.

\section{Materials and methods}

Patients and tissue samples. A total of 128 colon cancer tissue samples of different stages obtained between April 2011 and December 2011 were randomly collected from the Department of Gastrointestinal Surgery in The First People's Hospital of Changzhou, The Third Affiliated Hospital of Soochow University (Changzhou, Jiangsu, China). The selected tissue samples were routinely preserved in $10 \%$ buffered neutral formalin at $24^{\circ} \mathrm{C}$ for $12 \mathrm{~h}$. The normal tissues were removed from at least $5 \mathrm{~cm}$ away from the edge of these tumors. All cases of colon cancer were clinically and pathologically proven, and all of the patients recruited in this study had not received neoadjuvant chemotherapy or preoperative radiotherapy. All patients provided written informed consent prior to the collection and the research program used in the study was approved by the Ethical Committee of The Third Affiliated Hospital of Soochow University. Tumor, Node, Metastasis (TNM) stages and clinicopathological classification were defined based on the Union for International Cancer Control classification (12). 
Table I. Demographic and pathological parameters of colon cancer patients.

\begin{tabular}{|c|c|}
\hline Parameter & Value, n (\% \\
\hline \multicolumn{2}{|l|}{ Sex } \\
\hline Male & $86(67.2)$ \\
\hline Female & $42(32.8)$ \\
\hline \multicolumn{2}{|l|}{ Age, years } \\
\hline$\geq 60$ & $83(64.8)$ \\
\hline$<60$ & $45(35.2)$ \\
\hline \multicolumn{2}{|l|}{ Pathological type } \\
\hline Tubular adenocarcinoma & $63(49.2)$ \\
\hline Mucinous adenocarcinoma & $25(19.5)$ \\
\hline Papillary adenocarcinoma & $28(21.9)$ \\
\hline Squamous cell carcinoma & $12(9.4)$ \\
\hline \multicolumn{2}{|l|}{ Tumor location } \\
\hline Rectum and sigmoid colon & $65(50.8)$ \\
\hline Right colon & $37(28.9)$ \\
\hline Left colon & $26(20.3)$ \\
\hline \multicolumn{2}{|l|}{ Distant metastasis } \\
\hline Absent & $121(94.5)$ \\
\hline Present & $7(5.5)$ \\
\hline \multicolumn{2}{|l|}{ pT stage } \\
\hline $\mathrm{T} 1$ & $35(27.3)$ \\
\hline $\mathrm{T} 2$ & $20(15.6)$ \\
\hline $\mathrm{T} 3$ & $66(51.6)$ \\
\hline $\mathrm{T} 4$ & $7(5.5)$ \\
\hline \multicolumn{2}{|l|}{ pN stage } \\
\hline NO & $61(47.7)$ \\
\hline $\mathrm{N} 1+\mathrm{N} 2$ & $67(52.3)$ \\
\hline \multicolumn{2}{|l|}{ TNM stage } \\
\hline $\mathrm{I}$ & $40(31.2)$ \\
\hline II & $21(16.4)$ \\
\hline III & $60(46.9)$ \\
\hline IV & $7(5.5)$ \\
\hline \multicolumn{2}{|l|}{ Differentiation } \\
\hline High & $55(43.0)$ \\
\hline Moderate & $33(25.8)$ \\
\hline Poor & $40(31.2)$ \\
\hline
\end{tabular}

TNM, tumor-node-metastasis.

Patients received telephone follow-up or outpatient review until December 2016 or mortality.

Immunohistochemical analysis. Immunohistochemical staining was performed using the Elivsion two-step method (13). The following primary antibody was used: LRH-1 (1:100 dilution; catalog no. NBP1-90094; Novus Biologicals, LLC, Littleton, CO, USA). The secondary antibody (1:100 dilution; catalog no. kit-0028) and DAB solution were provided by Maxim Biomedical, Inc. (Fuzhou, China). All samples were fixed in $10 \%$ formalin at $24^{\circ} \mathrm{C}$ for $12 \mathrm{~h}$ solution and embedded in paraffin.
Table II. Expression of LRH-1 in colon cancer tissue and adjacent non-cancerous tissue (ANCTs).

\begin{tabular}{lrrrrr}
\hline & \multicolumn{2}{c}{$\begin{array}{c}\text { LRH-1 } \\
\text { expression }\end{array}$} & & \\
\cline { 2 - 3 } Tissues & Low & High & $\chi^{2}$ & P-value \\
\hline Colon cancer tissues, $n$ & 20 & 108 & 129.462 & $<0.001$ \\
ANCTs, $n$ & 111 & 17 & & \\
\hline
\end{tabular}

LRH-1, liver receptor homologue 1; ANCT, adjacent non-cancerous tissue.

Sections (3-4 mm) were dewaxed in xylene, dehydrated in ethanol (75, 95 and $100 \%$ ), and incubated in $3 \% \mathrm{H}_{2} \mathrm{O}_{2}$ for $15 \mathrm{~min}$ to destroy the activity of endogenous peroxidase. Following incubation in $10 \%$ bovine serum (dissolved in PBS at $24^{\circ} \mathrm{C}$; Novus Biologicals, LLC, Littleton, CO, USA) for $10 \mathrm{~min}$, each slide was incubated with the primary antibody at $4^{\circ} \mathrm{C}$ overnight. The aforementioned biotin-labeled mouse-rabbit immunoglobulin was selected as the secondary antibody. Staining using the DAB Detection kit (Polymer) (cat. no. kit-0014; Maxim Biomedical, Inc.) was performed according to the manufacturer's protocol, and sections positive for colon cancer were selected as positive controls, with non-immune animal serum IgG replacing the antibody as a negative control.

All tissue specimens were evaluated separately by two pathologists who were unaware of the clinicopathological status of the patients. Five high magnification fields of view were selected randomly from each section. The main expression of LRH-1 was found in the cytoplasm and shown as a tan or brown color. The scoring of the positive cell count fraction was determined as follows: Score $0, \leq 5$; score 1, 6-25; score 2, 26-50; score 3, 51-75; and score $4,>75 \%$. The scoring of the staining intensity and the dyeing depth was determined as follows: Score 0, no staining (colorless); score 1, weak staining (yellow); score 2, moderate staining (pale brown); and score 3 , strong staining (sepia). The total score was calculated by multiplying the staining intensity fraction with the positive cell count fraction. A total score of $<5$ was considered as negative expression of LRH-1, and a score of $\geq 5$ was considered as positive expression of LRH-1.

Statistical analysis. All statistical analyses were accomplished with the SPSS 17.0 statistical software (SPSS, Inc. Chicago, IL, USA). The association between LRH-1 expression and the clinicopathological characteristics was tested using the non-parametric $\chi^{2}$ test. The overall survival (OS) curves were plotted using the Kaplan-Meier method, and the positive and negative expression of LRH-1 samples was compared using the log-rank test. $\mathrm{P}<0.05$ was considered to indicate a statistically significant difference.

\section{Results}

Expression of LRH-1 in colon cancer tissues and adjacent normal tissues. The clinicopathological characteristics of the 

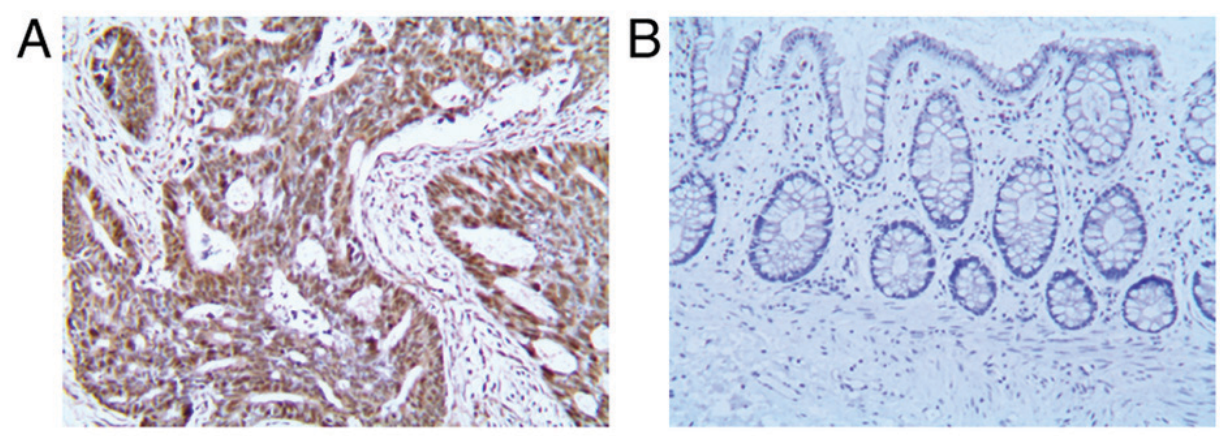

Figure 1. LRH-1 is highly expressed in colon cancer tissues. (A) Colon cancer tissues with a positive LRH-1 immunohistochemical reaction. (B) Adjacent normal tissues negative for LRH-1. Magnification, x200. LRH-1, liver receptor homologue 1.

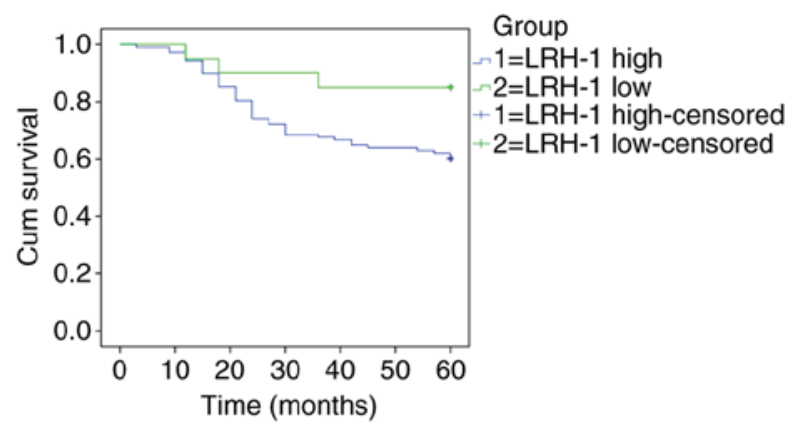

Figure 2. Kaplan-Meier survival curves for 128 colon cancer patients according to expression of LRH-1. LRH-1, liver receptor homologue 1.

128 patients who were recruited in the present study are shown in Table I. Among the patients, 42 were female and 86 were male, with a mean age of $58.38 \pm 8.3$ years (range, $38-82$ years). A total of 63 cases were tubular adenocarcinoma, 25 were mucinous adenocarcinoma, 28 were papillary adenocarcinoma and 12 were squamous cell carcinoma; 65 cases were located in the rectum and sigmoid colon, 37 in the right colon and 26 in the left colon. In terms of differentiation degree, 55 cases highly differentiated, 33 were moderately differentiated and 40 were poorly differentiated. The number of cases at stages I, II, III and IV was 40, 21, 60 and 7, respectively. The expression of LRH-1 in the 128 pairs of resected specimens (including tumor tissue samples and matched adjacent normal tissue samples) from patients who were diagnosed with colon cancer was determined by immunohistochemistry. It was found that 108/128 colon cancer tissues exhibited significantly LRH-1 expression higher compared with 17/128 adjacent non-cancerous tissue (Table II). The expression of LRH-1 in the colon cancer tissues was significantly higher than that in the adjacent tissues (Fig. 1).

Association of LRH-1 with different clinicopathological characteristics. The association between the expression level of LRH1 and the common clinicopathological parameters of colon cancer, including sex, age, TNM stage, pathological type, tumor location, degree of differentiation, depth of tumor invasion $(\mathrm{pT})$, lymph node metastasis $(\mathrm{pN})$ and distant metastasis, were analyzed (Table III). The level of LRH-1 expression was not found to be associated with the sex, age, tumor location, distant metastasis, degree of differentiation or pathological type of the colon cancer patients, but was significantly associated with the clinicopathological stage, depth of tumor invasion and lymph node metastasis.

Association between LRH-1 expression levels and the prognosis of patients. The 5-year OS rate of patients with negative and positive LRH-1 expression was investigated by Kaplan-Meier survival curves and the log-rank test, as shown in Fig. 2. A total score of $<5$ was considered as negative expression of LRH-1, and a score of $\geq 5$ was considered as positive expression of LRH-1Among the 128 patients who were followed up for 5 years, 2 were lost to follow-up. Of the 128 patients, 82 survived this period, and the 5-year OS rate was $64.1 \%$. Moreover, the 5 -year OS rates for patients with negative and positive LRH-1 expression were 85.0 and $60.2 \%$. The median estimated cumulative survival time was significantly lower in the LRH-1 positive expression group [46 months; 95\% confidence interval (CI), 42.729-49.938 months] compared with that in the LRH-1 negative expression group (54 months; 95\% CI, 48.106-60.494 months). These results suggest that patients with high levels of LRH-1 expression have a worse prognosis compared with patients with low levels of LRH-1 expression.

\section{Discussion}

The development of tumors and a variety of malignant behaviors are the outcome of the combined action of multiple genes, and in general, it is a complex multi-step and multi-factor process (14). The overexpression and activation of proto-oncogenes, the inhibition or downregulation of tumor suppressor genes and the downregulation of mutations serve an important role in the development of tumorigenesis. Excessive proliferation and blocked apoptosis are basic characteristics of tumor cells, which are associated with the regulation of proliferation, apoptosis and the cell cycle of important signal pathway disorders, and even loss of function $(15,16)$. Therefore, it is important to investigate the abnormal expression of genes associated with malignancy for determining tumor diagnosis, treatment and prognosis. In view of the abnormal expression of LRH-1 in a variety of malignant tumors (11), including gastric, breast and pancreatic cancer, the present study investigated the expression of LRH-1 in colon cancer and its association with the prognosis of patients.

LRH-1 is a member of the NR5A subfamily of NRs; it is expressed in numerous organs, including the liver, pancreas, 
Table III. Association between LRH-1 expression and clinicopathological features of colon cancer patients.

LRH-1 expression, $\mathrm{n}$

\begin{tabular}{|c|c|c|c|c|}
\hline Clinicopathological feature & Low & High & $\chi^{2}$ & P-value \\
\hline \multicolumn{5}{|l|}{ Sex } \\
\hline Male & 12 & 74 & 0.555 & 0.605 \\
\hline Female & 8 & 34 & & \\
\hline \multicolumn{5}{|l|}{ Age, years } \\
\hline$\geq 60$ & 16 & 67 & 2.389 & 0.136 \\
\hline$<60$ & 4 & 41 & & \\
\hline \multicolumn{5}{|l|}{ Pathological type } \\
\hline Tubular adenocarcinoma & 9 & 54 & 0.204 & 0.982 \\
\hline Mucinous adenocarcinoma & 4 & 21 & & \\
\hline Papillary adenocarcinoma & 5 & 23 & & \\
\hline Squamous cell carcinoma & 2 & 10 & & \\
\hline \multicolumn{5}{|l|}{ Tumor location } \\
\hline Rectum and sigmoid colon & 14 & 51 & 4.585 & 0.102 \\
\hline Right colon & 5 & 32 & & \\
\hline Left colon & 1 & 25 & & \\
\hline \multicolumn{5}{|l|}{ Distant metastasis } \\
\hline Absent & 20 & 101 & 1.371 & 0.371 \\
\hline Present & 0 & 7 & & \\
\hline \multicolumn{5}{|l|}{ pT } \\
\hline $\mathrm{T} 1$ & 8 & 27 & $4.878^{\mathrm{a}}$ & $0.030^{\mathrm{a}}$ \\
\hline $\mathrm{T} 2$ & 4 & 16 & & \\
\hline $\mathrm{T} 3$ & 8 & 58 & & \\
\hline $\mathrm{T} 4$ & 0 & 7 & & \\
\hline \multicolumn{5}{|l|}{$\mathrm{pN}$} \\
\hline No & 17 & 44 & 13.252 & $<0.001$ \\
\hline $\mathrm{N} 1+\mathrm{N} 2$ & 3 & 64 & & \\
\hline \multicolumn{5}{|l|}{ TNM stage } \\
\hline I & 12 & 28 & $13.252^{\mathrm{b}}$ & $<0.001^{\mathrm{b}}$ \\
\hline II & 5 & 16 & & \\
\hline III & 3 & 57 & & \\
\hline IV & 0 & 7 & & \\
\hline \multicolumn{5}{|l|}{ Differentiation } \\
\hline High & 10 & 45 & 5.677 & 0.055 \\
\hline Moderate & 1 & 32 & & \\
\hline Poor & 9 & 31 & & \\
\hline
\end{tabular}

${ }^{a}$ T1-T2 vs. T3-T4; ' I-II vs. III-IV. LRH-1, liver receptor homologue 1; TNM, tumor-node-metastasis.

colon and ovaries (6). LRH-1 serves an important role in the body, controlling the development and differentiation of animal embryos, the production of the steroid hormone and the metabolism of bile acid (17). LRH-1 exhibits increased expression in pancreatic cancer cells and can promote its proliferation by activating cyclin D1, cyclin E1 and c-Myc $(18,19)$. Furthermore, LRH-1 is highly expressed in breast cancer, promoting tumor cell growth via an increased synthesis of local estrogen (20). LRH-1 is involved in the renewal of intestinal cells in the gastrointestinal tract, and is expressed in gastric cancer and colon cancer cells. Zhang et al (21) found that LRH-1 gene polymorphisms (rs3790843 and rs3790844) increased the risk of local lymph node and distant metastasis. Kramer et al (22) confirmed the high expression of LRH-1 in colorectal cancer tissues and cells, and indicated that LRH-1 can promote the growth of colorectal cancer cells by inhibiting the expression of the cyclin-dependent kinase inhibitor 1A gene in the HCT116 and HT29 cell lines. Bayrer et al (23) showed that the inhibition of LRH-1 expression can weaken the ability of metastases of colon cancer cells, and can change the 
expression of associated genes. The present study found that colon cancer tissue exhibited positive LRH-1 expression, and the expression rate was $64.7 \%$, higher than that of the adjacent tissue at $32.2 \%$, which is consistent with the aforementioned results in pancreatic cancer and breast cancer. This indicates that the expression level of LRH-1 in colon cancer and other malignant tumors is abnormally elevated. Further analysis revealed that LRH-1 expression was associated with clinicopathological stage, depth of tumor invasion and lymph node metastasis; for example, the positive expression rate of LRH-1 in stage III and IV was $95.5 \%$, which was higher than that in stage I and II, suggesting that if the Tumor-Node-Metastasis (TNM) stage of colon cancer was higher then the positive expression rate would be higher. This study also found that the expression rate of LRH-1 in colon cancer tissues with T3+T4 depth was also higher than that in patients with lymph node metastasis and distant metastasis, and the expression of LRH-1 in patients with lymph node metastasis and distant metastasis was significantly higher than that in patients without lymph node metastasis. However, there is no cytological evidence that LRH-1 expression is directly involved in the malignant transformation of colon cancer and its transformation mechanism. Our next study intends to verify the effect of LRH-1 on colon cancer cells. In the present study, the 5-year survival rate was determined and it was found that LRH-1 positive expression was associated with poor prognosis. The median OS time of patients with positive expression was 46 months, which was lower than that of patients with negative expression at 54 months. The poor prognosis may be related to positive expression of LRH-1, associated with TNM stage, depth of invasion and lymph node metastasis.

In summary, LRH-1 is mainly expressed in colon cancer tissues, and is associated with the depth of tumor invasion, lymph node metastasis and clinicopathological stage. The prognosis of patients with positive LRH-1 expression is significantly worse than that of patients with negative expression. These results suggest that LRH-1 may serve an important role in the development and progression of colon cancer. The detection of LRH-1 expression can be used to assist in the diagnosis and evaluation of colon cancer.

\section{Acknowledgements}

The authors would like to thank Dr Hui Wang (The First People's Hospital of Changzhou, The Third Affiliated Hospital of Soochow University, Changzhou, China) for providing help with immunohistochemistry.

\section{Funding}

The present study was supported by the Applied Basic Research Project of Changzhou Science and Technology Bureau (grant no. CJ20140047) and Changzhou High-Level Medical Talents Training Project (grant no. 2016CZBJ046).

\section{Availability of data and materials}

The datasets used or analyzed during the present study are available from the corresponding author on reasonable request.

\section{Authors' contributions}

CW made substantial contribution to the conception and design of the present study, as well as the writing of the manuscript. JF made substantial contributions to the acquisition, analysis and interpretation of data for the present study and revised this article. ZL made substantial contributions to conception and design, analysis and interpretation of the data. ZL was involved in drafting the manuscript and revising it critically for important intellectual content.

\section{Ethics approval and consent to participate}

The research program used in the study was approved by the Ethical Committee of The Third Affiliated Hospital of Soochow University. Written informed consent was obtained from all study participants.

\section{Consent for publication}

Written informed consent was obtained from all study participants.

\section{Competing interests}

The authors declare that they have no competing interests.

\section{References}

1. Boerboom D, Pilon N, Behdjani R, Silversides DW and Sirois J: Expression and regulation of transcripts encoding two members of the NR5A nuclear receptor subfamily of orphan nuclear receptors, steroidogenic factor-1 and NR5A2, in equine ovarian cells during the ovulatory process. Endocrinology 141: 4647-4656, 2000.

2. Ikeda Y, Lala DS, Luo X, Kim E, Moisan MP and Parker KL: Characterization of the mouse FTZ-F1 gene, which encodes a key regulator of steroid hydroxylase gene expression. Mol Endocrinol 7: 852-860, 1993.

3. Stein S and Schoonjans K: Molecular basis for the regulation of the nuclear receptor LRH-1. Curr Opin Cell Biol 33: 26-34, 2015.

4. Lazarus KA, Wijayakumara D, Chand AL, Simpson ER and Clyne CD: Therapeutic potential of liver receptor homolog-1 modulators. J Steroid Biochem Mol Biol 130: 138-146, 2012.

5. Fayard E, Auwerx J and Schoonjans K: LRH-1: An orphan nuclear receptor involved in development, metabolism and steroidogenesis. Trends Cell Biol 14: 250-260, 2004.

6. Lee YK and Moore DD: Liver receptor homolog-1, an emerging metabolic modulator. Front Biosci 13: 5950-5958, 2008.

7. Out C, Hageman J, Bloks VW, Gerrits H, Sollewijn Gelpke MD, Bos T, Havinga R, Smit MJ, Kuipers F and Groen AK: Liver receptor homolog-1 is critical for adequate up-regulation of Cyp7a1 gene transcription and bile salt synthesis during bile salt sequestration. Hepatology 53: 2075-2085, 2011.

8. Venteclef N, Haroniti A, Tousaint JJ, Talianidis I and Delerive P: Regulation of anti-atherogenic apolipoprotein $\mathrm{M}$ gene expression by the orphan nuclear receptor LRH-1. J Biol Chem 283: 3694-3701, 2008

9. Oosterveer MH, Mataki C, Yamamoto H, Harach T, Moullan N, van Dijk TH, Ayuso E, Bosch F, Postic C, Groen AK, et al: LRH-1-dependent glucose sensing determines intermediary metabolism in liver. J Clin Invest 122: 2817-2826, 2012.

10. Stergiopoulos A and Politis PK: Nuclear receptor NR5A2 controls neural stem cell fate decisions during development. Nat Commun 7: 12230, 2016.

11. Nadolny C and Dong X: Liver receptor homolog-1 (LRH-1): A potential therapeutic target for cancer. Cancer Biol Ther 16: 996-1004, 2015.

12. Edge SB, Byrd DR, Compton CC, Fritz AG, Greene FL and Trotti A: AJCC Cancer Staging Manual. 7th edition, Springer, New York, 2010. 
13. Kang X, Zhang L, Wu R, Sheng X, Sun J and Chen X: The expression of prohibitin in gastrointestinal cancer tissue and its clinical signification. Laborat Med 21: 610-612, 2006.

14. Li YX, Zhang J, Qian Y, Meng CH, Wang HL, Tao XJ, Zhong S, Cao SX and Li QF: Molecular characterization, expression, polymorphism of NR5A2 and its relationship with litter size in $\mathrm{Hu}$ sheep. Genet Mol Res 14: 12765-12775, 2015.

15. Tan XH, Cheng R, Hu HP and Bai YP: Classification of colon cancer based on the expression of randomly selected genes. Genet Mol Res 14: 12628-12635, 2015.

16. Ding M, Li X and Qiu T: Combination of multiple gene markers to detect circulating tumor cells in the peripheral blood of patients with non-small cell lung cancer using real-time PCR. Genet Mol Res 14: 13033-13040, 2015.

17. Fernandez-Marcos PJ, Auwerx J and Schoonjans K: Emerging actions of the nuclear receptor LRH-1 in the gut. Biochim Biophys Acta 1812: 947-955, 2011.

18. Gao W, Tang Z, Zhang YF, Feng M, Qian M, Dimitrov DS and Ho M: Immunotoxin targeting glypican-3 regresses liver cancer via dual inhibition of Wnt signalling and protein synthesis. Nat Commun 6: 6536, 2015.

19. Benod C, Vinogradova MV, Jouravel N, Kim GE, Fletterick RJ and Sablin EP: Nuclear receptor liver receptor homologue 1 (LRH-1) regulates pancreatic cancer cell growth and proliferation. Proc Natl Acad Sci USA 108: 16927-16931, 2011.
20. Falender AE1, Lanz R, Malenfant D, Belanger L and Richards JS: Differential expression of steroidogenic factor-1 and FTF/LRH-1 in the rodent ovary. Endocrinology 144: 3598-3610, 2003

21. Zhang X, Gu D, Du M, Wang M, Cao C, Shen L, Kuang M, Tan Y, Huo X, Gong W, et al: Associations of NR5A2 gene polymorphisms with the clinicopathological characteristics and survival of gastric cancer. Int J Mol Sci 15: 22902-22917, 2014.

22. Kramer HB, Lai CF, Patel H, Periyasamy M, Lin ML, Feller SM, Fuller-Pace FV, Meek DW, Ali S and Buluwela L: LRH-1 drives colon cancer cell growth by repressing the expression of the CDKN1A gene in a p53-dependent manner. Nucleic Acids Res 44: 582-594, 2016.

23. Bayrer JR, Mukkamala S, Sablin EP, Webb P and Fletterick RJ: Silencing LRH-1 in colon cancer cell lines impairs proliferation and alters gene expression programs. Proc Natl Acad Sci USA 112: 2467-2472, 2015 .

c) (i) $(-)$ This work is licensed under a Creative Commons c) ${ }_{\mathrm{EY}} \mathrm{NO}$ ND Attribution-NonCommercial-NoDerivatives 4.0 International (CC BY-NC-ND 4.0) License. 